\title{
Detection of plastic strain using GNSS data of pre- and post-seismic deformation of the 2011 Tohoku-oki earthquake
}

\author{
Yukitoshi Fukahata ${ }^{1 *}$ (D), Angela Meneses-Gutierrez ${ }^{2,3}$ and Takeshi Sagiya ${ }^{3,4}$
}

\begin{abstract}
In general, there are three mechanisms causing crustal deformation: elastic, viscous, and plastic deformation. The separation of observed crustal deformation to each component has been a challenging problem. In this study, we succeed in separating plastic deformation as well as viscous deformation in the northern Niigata-Kobe Tectonic Zone (NKTZ), central Japan, using GNSS data before and after the 2011 Tohoku-oki earthquake, under the assumptions that elastic deformation is principally caused by the plate coupling along the Japan trench and that plastic deformation ceased after the Tohoku-oki earthquake due to the stress drop caused by the earthquake. The cessation of plastic deformation can be understood with the concept of stress shadow used in the field of seismic activity. The separated strain rates are about 30 nanostrain/year both for the plastic deformation in the preseismic period and for the viscous deformation in both the pre- and post-seismic periods, which means that the inelastic strain rate in the northern NKTZ is about 60 and 30 nanostrain/year in the pre- and post-seismic periods, respectively. This result requires the revision of the strain-rate paradox in Japan. The strain rate was exceptionally faster before the Tohoku-oki earthquake due to the effect of plastic strain, and the discrepancy between the geodetic and geologic strain rates is much smaller in usual time, when the plastic strain is off. In order to estimate the onset timing of plastic deformation, the information on stress history is essentially important.
\end{abstract}

Keywords: Plastic strain, Inelastic strain, NKTZ, Tohoku-oki earthquake, $\triangle C F F$, Strain-rate paradox

\section{Introduction}

\section{Basic mechanisms of crustal deformation}

We generally consider the following three mechanisms for crustal deformation: elastic, viscous, and plastic deformation. Considering a one-dimensional case for simplicity, we can express the constitutive equation for elastic deformation as

$$
\Delta \varepsilon=\Delta \sigma / k,
$$

where $k$ is an elastic modulus, $\varepsilon$ and $\sigma$ denote strain and stress, respectively, and $\Delta$ represents the change from an initial condition.

\footnotetext{
*Correspondence: fukahata@rcep.dpri.kyoto-u.ac.jp

${ }^{1}$ Disaster Prevention Research Institute, Kyoto University, Gokaho, Uji,

Kyoto 611-0011, Japan

Full list of author information is available at the end of the article
}

The constitutive equation for viscous deformation is

$$
\dot{\varepsilon}=A \sigma^{n},
$$

where $n$ is the stress exponent, $A$ is a coefficient that depends on various parameters, such as the temperature and grain size, and the dot denotes the differentiation with respect to time.

Plastic deformation occurs when the applied stress $\sigma$ exceeds the yield strength $s$ of a material:

$$
\Delta \varepsilon>0 \text { when } \sigma \geq s .
$$

This condition can be applicable not only to brittle deformation associated with earthquakes, but also to aseismic plastic flow.

The viscous deformation and the plastic deformation are collectively called inelastic deformation. As shown 
in Eqs. (1)-(3), crustal deformation generally depends on the change of stress state (elastic deformation) and the level of absolute stress (inelastic deformation). As explained later, however, stress history is crucially important in understanding actual crustal deformation.

Geodetic data, which measure crustal deformation, include the deformation due to all these three mechanisms, and the separation of each component has been an important problem. In a simple form, this problem arises in the analysis of crustal deformation after a large earthquake, or more generally, during an earthquake cycle. Fukahata et al. (2004) developed an inversion method to separately estimate elastic deformation due to slip on the plate interface and viscous deformation due to the viscoelastic relaxation during an earthquake cycle, and they applied the method to leveling data associated with the cycle of the interplate earthquakes along the Nankai Trough. Soon, Ito and Hashimoto (2004) followed them. Yamagiwa et al. (2015) applied the method developed by Fukahata et al. (2004) to GNSS data associated with the co- and post-seismic deformation of the 2011 Tohoku-oki earthquake. Gunawan et al. (2014) also separately estimated the effects of viscoelastic relaxation and after slip on the postseismic deformation of the 2004 Sumatra-Andaman earthquake.

The separation of these components in general form has been more difficult. However, Noda and Matsu'ura (2010) developed a formulation to separately estimate elastic deformation and inelastic deformation from observed geodetic data. Applying the formulation to GNSS data in the Niigata-Kobe Tectonic Zone (NKTZ), central Japan, they showed that volumetric strain in this region is mostly due to elastic deformation while shear strain is mostly due to inelastic deformation.

Recently, from the comparison of GNSS data in the northern NKTZ (Fig. 1: the area enclosed by dashed lines in Fig. 1c, d) before and after the 2011 Tohoku-oki earthquake, Meneses-Gutierrez and Sagiya (2016) have successfully separated inelastic deformation from observed geodetic data. In this study, they have considered that the long-wavelength deformation is essentially due to elastic deformation, because its principal source is located on the plate interface between the Pacific plate and the continental plate, which is several hundred kilometers away from the NKTZ. The strain-rate paradox of Japan (Ikeda 1996; Kaizuka and Imaizumi 1984), the geodetically estimated east-west $(\mathrm{E}-\mathrm{W})$ contraction rate is nearly one order faster than the geological one, is also strongly related to this separation problem, because the geodetic data include deformation of all the mechanisms, while the geologically estimated contraction rate only reflects inelastic deformation.

As we have seen, the separation of elastic and inelastic deformation has been done by several studies. However, the separation of inelastic deformation into viscous deformation and plastic deformation has remained an even more challenging problem.

\section{Seismic activity and $\triangle$ CFF}

In the field of seismic activity, the phenomenon of stress shadow, which can be quantitatively evaluated by $\triangle \mathrm{CFF}$, is well known. For example, after the 2011 Tohoku-oki earthquake, seismic activity in most inland regions has significantly dropped. This phenomenon can be well explained by $\triangle$ CFF (e.g., Toda et al. 2011), because the Tohoku-oki earthquake resulted in the negative change of CFF on most active faults in inland regions.

The concept of stress shadow and $\triangle \mathrm{CFF}$ is also useful to understand seismic activity for much longer time scales. Japan has historical records for more than 1000 years. The records show that large interplate earthquakes along the Nankai Trough, which are called the Nankai earthquakes, have repeatedly happened in western Japan, with the interval of about 100-200 years (e.g., Ando 1975). Historical records also show that the frequency of large inland earthquakes in western Japan is significantly higher for 50 years before and 10 years after the Nankai earthquakes (Utsu 1974; Shimazaki 1976; Hori and Oike 1996). In order to explain this seismic activity, Hori and Oike (1999) introduced the concept of stress shadow and $\triangle \mathrm{CFF}$. That is to say, the Nankai earthquake causes increase of $\triangle \mathrm{CFF}$ on some active faults, which results in not a few large inland earthquakes just after the Nankai earthquake; on the other hand, $\triangle \mathrm{CFF}$ on other active faults significantly decreases, which prevents the occurrence of large inland earthquakes until the next Nankai earthquake approaches. Shikakura et al. (2014) employed a viscoelastic response function (Fukahata and Matsu'ura 2006) to more accurately evaluate the stress change due to the Nankai earthquakes, and have shown that the activity of large inland earthquakes that happened in western Japan for the last 500 years can be very well explained by $\triangle \mathrm{CFF}$, that is to say, almost all the earthquakes happened when the $\triangle \mathrm{CFF}$ of respective faults renewed the highest value.

When an earthquake happens, some crustal deformation always occurs. In other words, seismic activity is inevitably related to crustal deformation, more specifically to plastic deformation.

\section{Crustal deformation in the NKTZ}

Through the analysis of GNSS data, Sagiya et al. (2000) recognized the NKTZ as a region of large strain rate 


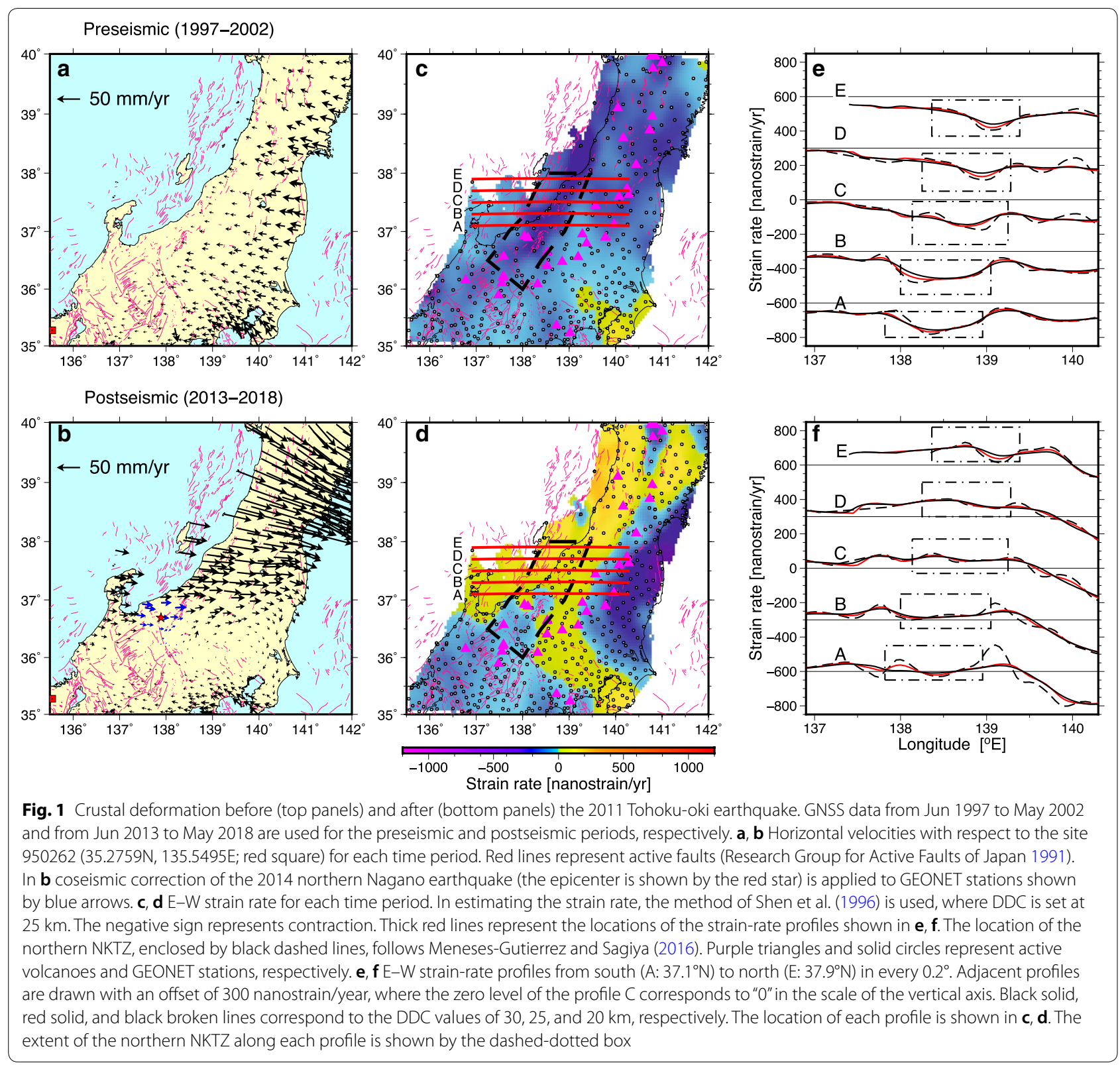

that passes through central Japan. As mentioned above, Meneses-Gutierrez and Sagiya (2016) have successfully separated inelastic deformation from observed GNSS data around the Niigata plain in the northern NKTZ. Following the study, to quantitatively explain the observed GNSS data, Meneses-Gutierrez et al. (2018) have constructed a model that has an aseismic fault embedded in an elastically heterogeneous medium. Because the study also mainly focused on the separation of the elastic and inelastic deformation, it paid relatively less attention on the difference of inelastic strain rates before and after the Tohoku-oki earthquake.
However, when we examine the observed GNSS data in detail, we can notice that the separated inelastic strain rate is significantly faster before the Tohoku-oki earthquake. Meneses-Gutierrez et al. (2018) tried to interpret this observation with a combination of persistent inelastic deformation and elastic heterogeneity effect. However, a possibility of significant temporal change of inelastic deformation has not been seriously considered. The change of the inelastic strain rate is difficult to be explained as long as we only consider the viscous flow as a mechanism of crustal deformation, because the viscous flow depends on the absolute 
stress level (Eq. 2) and the stress change due to the 2011 Tohoku-oki earthquake in this area is less than $0.5 \mathrm{MPa}$ (Yoshida et al. 2012), which is considered to be much smaller than the absolute stress.

On the other hand, if we consider that the concept of stress shadow and $\triangle \mathrm{CFF}$ could be applicable to this case, we can reasonably explain the change of strain rate. The strain rate was faster before the Tohoku-oki earthquake due to plastic deformation because $\triangle$ CFF renewed the highest value on many faults in this region, while it is slower after the earthquake because the stress level was dropped due to the 2011 Tohoku-oki earthquake, which resulted in the cessation of plastic deformation.

If we accept this concept, the strain-rate paradox of Japan would be viewed differently, that is to say, the strain rate was exceptionally faster before the 2011 Tohoku-oki earthquake, and that the discrepancy between the geodetically measured and geologically estimated strain rates is much smaller after the 2011 Tohoku-oki earthquake.

In the following, we first explain the data used in this study. Next, we develop a formulation to differentiate plastic deformation and viscous deformation from observed geodetic data and show the result. Finally, we discuss geological and geophysical implications of the obtained result.

\section{Data}

Following Meneses-Gutierrez and Sagiya (2016), we analyze daily coordinates of GEONET sites provided by the Geospatial Information Authority of Japan (GSI) before and after the 2011 Tohoku-oki earthquake. To measure the change in the crustal deformation, we use the data spanning from June 1997 to May 2002 for the preseismic period (top panels of Fig. 1). After the 2011 Tohoku-oki earthquake, there has been a significant trend (larger extension in the east) in the $\mathrm{E}-\mathrm{W}$ strain rate, but the trend became much smaller in the northern NKTZ a few years after the 2011 Tohoku-oki earthquake. So, we use the data from June 2013 to May 2018 for the postseismic period (bottom panels of Fig. 1). During these periods, there happened no large earthquakes that affected crustal deformation in the area of interest except for the $2014 M_{\mathrm{w}} 6.2$ northern Nagano earthquake. Coseismic displacements associated with this earthquake were corrected for GEONET data at the stations where coseismic offsets were observed (blue arrows in Fig. 1b).

We calculate horizontal velocities at all stations with respect to the site $950262(35.2759 \mathrm{~N}, 135.5495 \mathrm{E})$ by linear regression for the preseismic and postseismic periods (Fig. 1a, b, respectively). From the calculated horizontal velocities at the GEONET sites, we estimate strain rate distribution using the method of Shen et al. (1996). The estimated strain rates are shown by colors in Fig. 1c, d, in which the component of E-W strain rate is shown, recalling that the NKTZ is essentially characterized by E-W contraction. Here, the negative sign represents contraction. In estimating strain rates by the method of Shen et al. (1996), we have to determine a distance decaying constant (DDC), which controls weighting among observation sites. In Fig. 1c, d, we use the DDC value of $25 \mathrm{~km}$ in accordance with the approximate distance between GEONET stations. However, the DDC value can affect the estimation of strain rate. Therefore, in the strain rate profiles (Fig. 1e, f), which are taken in the E-W direction as shown in Fig. 1c, d, we also show the cases of $20 \mathrm{~km}$ and $30 \mathrm{~km}$ for the DDC.

\section{Formulation}

We consider that crustal deformation is generally caused by elastic, viscous, and plastic deformation. Therefore, we can express a geodetically observed strain rate $d$ as

$$
d=V_{\mathrm{E}}+V_{\mathrm{V}}+V_{\mathrm{P}}
$$

where $V_{\mathrm{E}}, V_{\mathrm{V}}$, and $V_{\mathrm{P}}$ represent strain rates due to elastic, viscous, and plastic deformation, respectively. Following Meneses-Gutierrez and Sagiya (2016) and MenesesGutierrez et al. (2018), we separate the deformation into long-wavelength and short-wavelength components:

$$
d=d_{\mathrm{L}}+d_{\mathrm{S}} ; V_{i}=V_{i \mathrm{~L}}+V_{i \mathrm{~S}} \quad(i=E, V, P),
$$

where subscripts L and S denote long- and short-wavelength components, respectively.

Elastic deformation is principally caused by the plate coupling along the Japan trench. The northern NKTZ, the region analyzed in this study, is several hundred kilometers away from it. Hence, for simplicity, we assume as

$$
V_{\mathrm{ES}} \approx 0,
$$

where $V_{\mathrm{ES}}$ represents the short-wavelength component of the elastic strain rate. In fact, elastic heterogeneity in the NKTZ results in non-negligible $V_{\mathrm{ES}}$, which is treated as a correction term in the later sections (see also Appendix). In addition to Eq. (6), as we have argued, the plastic strain is considered to stop because of stress shadow after the Tohoku-oki earthquake:

$$
V_{\mathrm{PL}}^{\mathrm{a}} \approx V_{\mathrm{PS}}^{\mathrm{a}} \approx 0,
$$

where the superscript $a$ denotes the strain rate after the Tohoku-oki earthquake.

Therefore, we can rewrite Eq. (4) for before (b) and after (a) the Tohoku-oki earthquake, respectively, as

$$
d_{\mathrm{S}}^{\mathrm{b}} \approx V_{\mathrm{VS}}^{\mathrm{b}}+V_{\mathrm{PS}}^{\mathrm{b}}
$$




$$
d_{\mathrm{S}}^{\mathrm{a}} \approx V_{\mathrm{VS}}^{\mathrm{a}}
$$

As mentioned above, the stress change due to the 2011 Tohoku-oki earthquake in the northern NKTZ is less than 0.5 MPa (Yoshida et al. 2012), which is considered to be much smaller than the absolute stress level. Because the viscous strain is controlled by the absolute stress, we can reasonably assume that

$$
V_{\mathrm{VS}}^{\mathrm{b}} \approx V_{\mathrm{VS}}^{\mathrm{a}}
$$

In the end, from Eqs. (8)-(10), we obtain the plastic strain rate of the short-wavelength component as

$$
V_{\mathrm{PS}}^{\mathrm{b}} \approx d_{\mathrm{S}}^{\mathrm{b}}-d_{\mathrm{S}}^{\mathrm{a}}
$$

With this equation, we can quantitatively estimate the plastic strain rate from observed data, although its longwavelength component remains unknown.

\section{Results}

In order to separate long-wavelength components, Meneses-Gutierrez and Sagiya (2016) and Meneses-Gutierrez et al. (2018) used a moving average filter. In this study, instead of it, the offset component (DC component) is subtracted (or added) from the strain rate profiles shown in Fig. 1e, f, because it is simpler and, more importantly, the offset component unambiguously corresponds to the longest wavelength component on the basis of the Fourier analysis.

For the preseismic period, as a long-wavelength component, we add 50, 40, 70, 80, and 70 nanostrain/year for each profile from south $\left(37.1^{\circ} \mathrm{N}\right)$ to north $\left(37.9^{\circ} \mathrm{N}\right)$. For the postseismic period, we subtract 40, 70, 70, 80, and 110 nanostrain/year for each profile from south to north. After adding or subtracting the long-wavelength component, the short-wavelength component remains, which is shown in Fig. 2. Solid and broken lines represent the strain rate profiles of the preseismic and postseismic periods, respectively. The region of the NKTZ is shown by the dashed-dotted box. In determining the long-wavelength component to add or subtract, we assume that the rheological property of the surrounding region of the NKTZ is relatively normal in comparison to the NKTZ. Specifically, the strain rate is adjusted to be roughly zero to the west of the NKTZ, where the effect of the subduction of the Pacific plate is small; to the east of the NKTZ, where we observed large spatial variation in strain rates especially for the postseismic period (Fig. 1d), the maximum strain rate is adjusted to be roughly zero by subtracting or adding the long-wavelength component.

As shown in Fig. 2, the contraction rate in the northern NKTZ is significantly faster for the preseismic period than for the postseismic period. Within

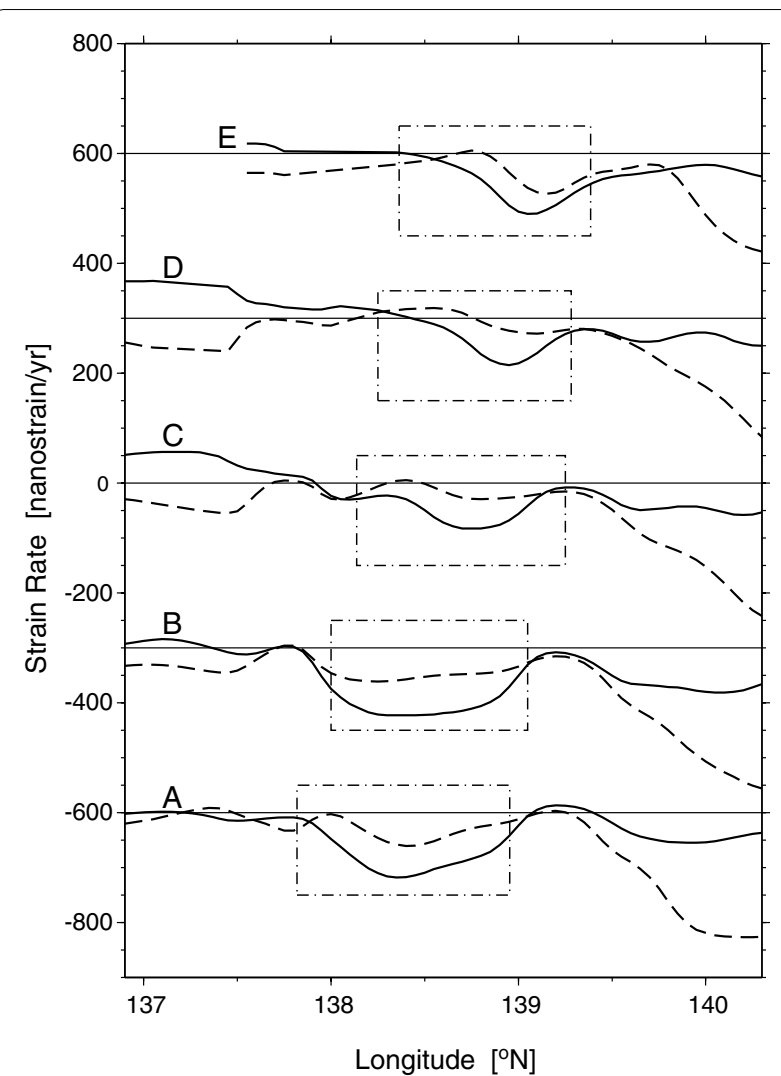

Fig. 2 E-W strain rate profiles for the preseismic (1997-2002; solid line) and postseismic (2013-2018; broken line) periods. These profiles are obtained by adding or subtracting offset (DC) components from the strain rate profiles shown in Fig. 1e, $\mathrm{f}$ (see the text). Note that the offset component corresponds to the longest wavelength component. The locations of the profiles, which are taken from $37.1^{\circ} \mathrm{N}$ (profile A) to $37.9^{\circ} \mathrm{N}$ (profile E) every $0.2^{\circ}$, are shown in Fig. 1. Adjacent profiles are drawn with an offset of 300 nanostrain/year, where the zero level of the profile C corresponds to " 0 " in the scale of the vertical axis. The dashed-dotted box on each profile shows the region of the northern NKTZ

the northern NKTZ, the average strain rate is about 65 nanostrain/year for the preseismic period, while it is about 25 nanostrain/year for the postseismic period. By applying Eqs. (9)-(11) to these results, we obtain, for short-wavelength components in the northern NKTZ, the plastic strain rate for the preseismic period, $V_{\mathrm{PS}}^{\mathrm{b}}$, to be about 40 nanostrain/year and the viscous strain rate both for the pre- and post-seismic periods, $V_{\mathrm{VS}}^{\mathrm{a}}\left(V_{\mathrm{VS}}^{\mathrm{b}}\right)$, to be about 25 nanostrain/year.

As mentioned above, however, we need to consider the effect of elastic heterogeneity in the NKTZ, which decreases $V_{\mathrm{PS}}^{\mathrm{b}}$ while increases $V_{\mathrm{VS}}^{\mathrm{a}}$, because the shortwavelength component of the elastic strain rate is basically proportional to the long-wavelength component. In "Appendix" we explain the derivation of the 
correction terms, which are about 6.8 nanostrain/year or slightly smaller for $V_{\mathrm{PS}}^{\mathrm{b}}$ and about 3.1 nanostrain/year or slightly larger for $V_{\mathrm{VS}}^{\mathrm{a}}$. In the end, both the preseismic plastic strain rate and the pre- and post-seismic viscous strain rates are about 30 nanostrain/year. Then, the inelastic strain rates for the pre- and post-seismic periods are about 60 and 30 nanostrain/year, respectively.

\section{Discussion}

As mentioned above, the strain rate calculated from observed GNSS data depends on the value of DDC. For smaller DDC, the resolution becomes better, while the result becomes unstable. Usually, the change of calculated strain rates is gradual for the change of DDC. However, we can notice some sudden changes in Fig. 1 for $\mathrm{DDC}=20 \mathrm{~km}$ (the most conspicuous example is profile A of Fig. 1f), which suggests overfitting to observed data. On the other hand, the profiles for $\mathrm{DDC}=25 \mathrm{~km}$ and $30 \mathrm{~km}$ are quite similar. Therefore, we consider $25 \mathrm{~km}$ is good as a value of DDC in the analysis of this study. Incidentally, the difference of the average strain rate in the northern NKTZ is less than a few nanostrain/year for the cases of DDC $=25 \mathrm{~km}$ and $30 \mathrm{~km}$. The width of the NKTZ, shown in Figs. 1 and 2, can have a non-negligible effect on the estimation of strain rate. In general, if we take a wider region as the NKTZ, the estimated strain rate becomes smaller, while if we take a narrower region, the rate becomes larger. In this study, in order to avoid this ambiguity, we strictly follow the definition of Meneses-Gutierrez and Sagiya (2016) for the location of the NKTZ.

As shown in Fig. 2, the strain rate in the preseismic period is significantly faster than that in the postseismic period. Therefore, the strain-rate paradox (Ikeda 1996; Kaizuka and Imaizumi 1984) is needed to be reviewed. Ikeda (1996) drew a famous diagram that shows the time development of geodetic and geological (=inelastic) strain in inland Japan, with which Ikeda (1996) clearly described the problem of the strain-rate paradox and predicted the occurrence of a gigantic earthquake along the Japan trench to solve the paradox (unfortunately, the prediction became a reality in 2011 as the Tohoku-oki earthquake). Ikeda's idea is shown by thin lines in Fig. 3; the thin solid line represents the geodetic strain that includes all components of strain, while the thin broken line represents the geological strain, which is equal to the inelastic strain. The elastic strain is released by the gigantic earthquake, while the inelastic strain monotonically accumulates in time. As shown by thin lines in Fig. 3, Ikeda (1996) assumed constant strain rates for the periods before and after the gigantic earthquake. As demonstrated in Fig. 2, however, the strain rate is not constant but faster before the gigantic earthquake due to the effect

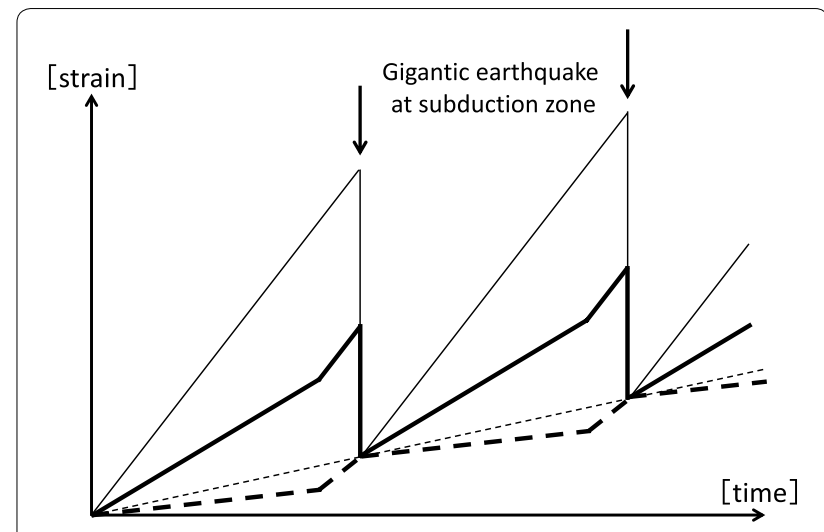

Fig. 3 Conceptual model of the time development of strain in the upper crust of inland Japan. The idea of Ikeda (1996) is shown by thin lines, while thick lines represent the revision by this study, which includes the change of strain rates before a gigantic earthquake due to the onset of plastic deformation. The solid line represents the geodetic strain that includes all components of strain. The broken line represents inelastic (geological) strain, which is composed of plastic and viscous strain. The elastic strain is released by the gigantic earthquake, while the inelastic strain monotonically accumulates with time

of plastic strain. Therefore, the relation between strain and time should be revised; the revised one is shown by thick lines in Fig. 3, where faster strain rates due to the onset of plastic strain are reflected to both the geodetic and the geological strain rates.

The strain-rate paradox originates from a large gap (about one order) between the geodetically estimated strain rate and the geologic one. The geodetically observed strain rate for the preseismic period is about 100-200 nanostrain/year in the NKTZ (Nakane 1973; Hashimoto 1990; Sagiya et al. 2000), while the geologically estimated strain rate is less than 25 nanostrain/year in regional averages (Wesnousky et al. 1982; Kaizuka and Imaizumi 1984). However, Fig. 3 requires a substantial change on this view. The results of Figs. 1 and 2 show that, before the 2011 Tohoku-oki earthquake, the strain rate of the short-wavelength component, $d_{\mathrm{S}}^{\mathrm{b}}$, is about 65 nanostrain/year and that of the long-wavelength component, $d_{\mathrm{L}}^{\mathrm{b}}$, which corresponds to the offset components used to obtain the strain rate profiles of Fig. 2, is about 60 nanostrain/year in average. Then, the total strain rate is about 125 nanostrain/year, which is consistent with the previous reports (Nakane 1973; Hashimoto 1990; Sagiya et al. 2000). As mentioned in the previous section, the inelastic strain rate of the short-wavelength component is about 60 nanostrain/year before the earthquake. Inelastic deformation may also be included in the long-wavelength component. In brief, the inelastic strain rate is comparable to the elastic strain rate before the earthquake. In other words, the strain rate is considered to have been 
exceptionally faster before the 2011 Tohoku-oki earthquake due to the effect of plastic strain, and the apparent discrepancy between the geodetic and geologic strain rates was larger. If this idea is correct, the localized shortening of NKTZ after finishing the viscoelastic relaxation of the Tohoku-oki earthquake will be significantly slower than that before the 2011 Tohoku-oki earthquake.

Ikeda (1996) also drew an interesting diagram that showed the time development of stress in the upper crust in inland Japan. Figure 4 shows his idea with a modification of the zero stress level; the stress just after a gigantic earthquake was taken to be zero in his original diagram. Ikeda (1996) considered that at first the stress linearly increases with time after a gigantic earthquake; when the stress reaches around the strength of the upper crust, however, inland earthquakes frequently happen and further increase of stress is suppressed. We basically agree with his view, although we consider that not only inland earthquakes but also aseismic deformation contributes to suppressing the stress increase, as exemplified in western Japan by Shikakura et al. (2014). The timing when the stress reaches the strength of the upper crust corresponds to the onset of plastic strain. In Fig. 4, if inland earthquakes frequently happen, then the strain rate should also increase, but this effect was not included in his strain-time diagram (thin lines in Fig. 3). In other words, the revised strain-time relation (thick lines in Fig. 3) takes this effect into account.

Plastic deformation occurs when the applied stress reaches the strength of the material, but it is generally difficult to know both absolute stress and crustal strength. However, Figs. 3 and 4 mean that, instead of these values, the history of stress is essentially important

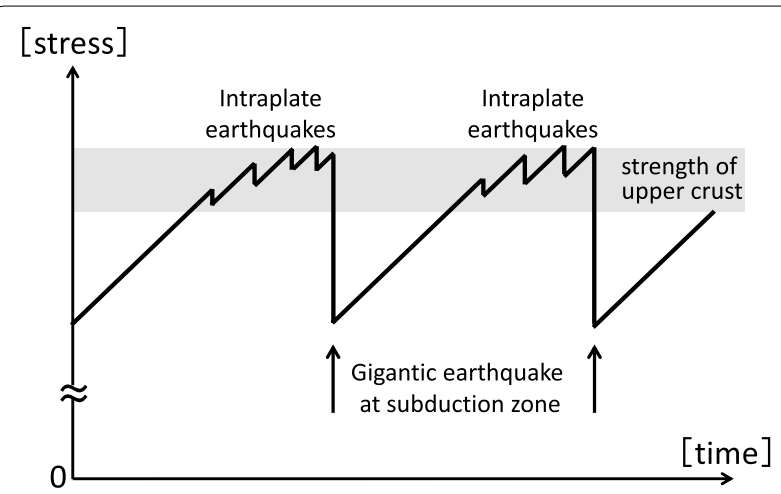

Fig. 4 Conceptual model of the time development of stress in the upper crust of inland Japan. The diagram follows Ikeda (1996) with a modification of the zero stress level; the stress just after a gigantic earthquake was taken to be zero in his original diagram. Ikeda (1996) considers that the stress increase is suppressed by the occurrence of intraplate earthquakes before a gigantic earthquake at subduction zone to understand the onset timing of plastic deformation. When the total stress increase after a gigantic earthquake becomes comparable to the coseismic stress release due to the gigantic earthquake, plastic deformation is likely to start. In this meaning, occurrence of plastic deformation depends on the stress history. The onset timing of plastic strain is important to understand the crustal activity in inland Japan. According to the catalogue of historical earthquakes (Utsu 1990), the region of the northern NKTZ certainly has a significantly larger number of large earthquakes in the last few hundred years than before. However, because the temporal uniformity of the historical records is not guaranteed, it is difficult to judge the onset timing of plastic strain from the record.

If we focus on just before and after the 2011 Tohokuoki earthquake, faster strain rates in the preseismic period are consistent with the seismic activity observed in inland regions of northeastern and central Japan. In these regions large inland earthquakes, such as the 2004 $M_{\mathrm{w}} 6.6$ Chuestu, the $2007 M_{\mathrm{w}} 6.6$ Chuetsu-oki, and the $2008 M_{\mathrm{w}} 6.9$ Iwate-Miyagi inland earthquakes, happened before the 2011 Tohoku-oki earthquake, although we also had the $2014 M_{\mathrm{w}} 6.2$ northern Nagano earthquake, and the $2019 M_{\mathrm{w}} 6.4$ Yamagata-oki earthquake after the Tohoku-oki earthquake. Particularly, the Yamagata-oki earthquake is enigmatic. The occurrence of this earthquake cannot be understood from usual $\triangle C F F$ theory. When we recall that almost all inland earthquakes in western Japan for the last 500 years can be very well explained by $\triangle \mathrm{CFF}$ (Shikakura et al. 2014), the 2019 Yamagata-oki earthquake might be a very rare example. Increase of pore fluid pressure (Terakawa et al. 2013) triggered by the Tohoku-oki earthquake might be responsible for the occurrence of this earthquake.

As mentioned in "Formulation" section, it is difficult to estimate the long-wavelength component of plastic and viscous strain rates. Meneses-Gutierrez and Sagiya (2016) also separated only the short-wavelength component of inelastic deformation. Although the separation of these strain rates from elastic strain rate for long-wavelength components is a challenging problem, it is possible to put an upper limit on them. First, they must be smaller than the observed long-wavelength component before the earthquake, $d_{\mathrm{L}}^{\mathrm{b}}$, which is about 60 nanostrain/ year, as mentioned above. In addition, elastic deformation would be dominant in the deformation of the longwavelength component, considering that the long-wavelength deformation completely changed from contraction to extension due to the 2011 Tohoku-oki earthquake. Hence, the plastic and viscous strain rates should be smaller than a half of $d_{\mathrm{L}}^{\mathrm{b}}, 30$ nanostrain/year (because $\left|V_{\mathrm{PL}}^{\mathrm{b}}\right|<\left|V_{\mathrm{EL}}^{\mathrm{b}}\right|$ and $\left|V_{\mathrm{VL}}^{\mathrm{b}}\right|<\left|V_{\mathrm{EL}}^{\mathrm{b}}\right|$ ), and probably much smaller than 30 nanostrain/year. In fact, the 
obtained inelastic strain rates of the short-wavelength components (60 and 30 nanostrain/year before and after the Tohoku-oki earthquake, respectively) are roughly comparable to previous estimates of inelastic strain rate in and around the northern NKTZ. From the analysis of geological cross sections, Sato (1989) estimated the E-W strain rate to be $26-83$ nanostrain/year. From the deformation of the Philippine Sea slab, Fukahata (2019) estimated the contraction rate parallel to the Nankai trough to be 35-70 nanostrain/year. From slip rates on active faults, Wesnousky et al. (1982) and Kaizuka and Imaizumi (1984) estimated the E-W strain rate to be 3-25 nanostrain/year, although this would be a minimum estimate, because large inland earthquakes have often happened on faults that were previously not identified as active faults. Careful comparison with such estimates might give a clue to estimate the long-wavelength components of plastic and viscous strain rates.

It should be noted that inelastic deformation that occurs at depth (e.g., in the lower crust) results in elastic deformation in the shallow region (e.g., near the Earth's surface). In the analysis of this study, this elastic deformation, caused by inelastic deformation at depth in the northern NKTZ, is also counted as inelastic deformation, because it is technically difficult to distinguish them, and more importantly, this elastic deformation monotonically accumulates with time and is transformed into inelastic deformation (e.g., due to brittle failure) sometime in the future.

\section{Conclusions}

From the comparison of strain rate profiles in the northern NKTZ before and after the Tohoku-oki earthquake (Fig. 2), we succeeded in separating plastic and viscous strain rates of short-wavelength components. The obtained strain rate is about 30 nanostrain/year for the plastic strain rate in the preseismic period, about 30 nanostrain/year for the viscous strain rate in both the pre- and post-seismic periods, and about 60 and 30 nanostrain/year for the inelastic strain rate in the preseismic and postseismic periods, respectively. This result requires the revision of the strain-rate paradox in Japan (Fig. 3); the strain rate was exceptionally faster before the Tohoku-oki earthquake due to the effect of plastic strain, which ceased after the earthquake because of the stress shadow. Active plastic deformation in the preseismic period was suggested by Ikeda (1996) in the stresstime diagram (Fig. 4), but this effect was not taken into account in his strain-time diagram (Fig. 3). In oder to understand the onset timing of plastic deformation, the information on stress history is essentially important.

\section{Abbreviations}

CFF: Coulomb failure function; DC: Direct current; DDC: Distance decaying constant; E-W: East-west; GEONET: GNSS Earth Observation Network System; GNSS: Global Navigation Satellite System; GSI: Geospatial Information Authority of Japan; NKTZ: Niigata-Kobe tectonic zone.

\section{Acknowledgements \\ We are grateful to the Geospatial Information Authority of Japan (GSI) for providing GEONET GNSS data for this analysis. We also thank to the National Research Institute for Earth Science and Disaster Resilience (NIED) for the hypocenter location and to the United States Geological Survey (USGS) for moment magnitudes. Some figures were created with the GMT software (Wessel and Smith 1998).}

\section{Authors' contributions}

YF designed this study, carried out the analysis of strain rate profiles, and prepared the manuscript. AMG analyzed GNSS data and obtained the map of strain rate distribution. TS helped with the analyses and in preparing the manuscript. All authors discussed the results. All authors read and approved the final manuscript.

\section{Funding}

This study was supported by the Grant-in-Aid for Scientific Research (C) (Kakenhi No. 19K04017) and on Innovative Areas (Kakenhi No. 26109003) from the Ministry of Education, Culture, Sports, Science and Technology (MEXT) to YF and TS.

\section{Availability of data and materials}

The GNSS data analyzed are publicly provided by Geospatial Information Authority of Japan (GSI).

\section{Competing interests}

The authors declare that they have no competing interests.

\section{Author details}

1 Disaster Prevention Research Institute, Kyoto University, Gokaho, Uji, Kyoto 611-0011, Japan. ${ }^{2}$ Institute for Advanced Research, Nagoya University, Furo-cho, Chikusa-ku, Nagoya-shi 464-8601, Japan. ${ }^{3}$ Disaster Mitigation Research Center, Nagoya University, Furo-cho, Chikusa-ku, Nagoya-shi 464-8601, Japan. ${ }^{4}$ Graduate School of Environmental Studies,

Nagoya University, Furo-cho, Chikusa-ku, Nagoya 464-8601, Japan.

\section{Appendix \\ Effect of elastic heterogeneity in the NKTZ on the estimation of plastic strain rate}

In "Formulation" section, we neglected the short-wavelength component of elastic strain rate, for simplicity (Eq. 6). Ohzono et al. (2012) and Okada and Ikeda (2012), however, have pointed out that the elastic property of the NKTZ is significantly different from that of the surrounding area, which can lead to short-wavelength component in elastic deformation. In this Appendix, we quantitatively estimate the effects of the elastic heterogeneity on the plastic and viscous strain rates, which are used as correction terms in this study.

According to the analysis of GNSS data by MenesesGutierrez et al. (2018), the zone with about 10-20\% smaller elastic stiffness spanning the width of $30-40 \mathrm{~km}$ is needed in order to explain coseismic deformation data. Because the width of the NKTZ is taken to be about $100 \mathrm{~km}$ in this study, this effect corresponds to about $5 \%$ exaggeration of the elastic deformation in average within 
the NKTZ than the surrounding area. In other words, the relation between the short- and the long-wavelength components of elastic deformation can be written as

$$
V_{\mathrm{ES}} \approx c V_{\mathrm{EL}},
$$

where $c$ is about 0.05 .

When we cannot neglect the short-wavelength component of elastic deformation, Eqs. (8) and (9) become

$$
\begin{aligned}
& d_{\mathrm{S}}^{\mathrm{b}}=V_{\mathrm{ES}}^{\mathrm{b}}+V_{\mathrm{VS}}^{\mathrm{b}}+V_{\mathrm{PS}}^{\mathrm{b}}, \\
& d_{\mathrm{S}}^{\mathrm{a}} \approx V_{\mathrm{ES}}^{\mathrm{a}}+V_{\mathrm{VS}}^{\mathrm{a}} .
\end{aligned}
$$

From Eqs. (10), (A2), and (A3), we obtain

$$
V_{\mathrm{PS}}^{\mathrm{b}} \approx d_{\mathrm{S}}^{\mathrm{b}}-d_{\mathrm{S}}^{\mathrm{a}}-\left(V_{\mathrm{ES}}^{\mathrm{b}}-V_{\mathrm{ES}}^{\mathrm{a}}\right) .
$$

With Eq. (7), we can obtain the same relations as (A2) and (A3) for the long-wavelength components:

$$
\begin{aligned}
& d_{\mathrm{L}}^{\mathrm{b}}=V_{\mathrm{EL}}^{\mathrm{b}}+V_{\mathrm{VL}}^{\mathrm{b}}+V_{\mathrm{PL}}^{\mathrm{b}}, \\
& d_{\mathrm{L}}^{\mathrm{a}} \approx V_{\mathrm{EL}}^{\mathrm{a}}+V_{\mathrm{VL}}^{\mathrm{a}} .
\end{aligned}
$$

Even if we consider a wider area that spans the whole width of the strain-rate profiles shown in Fig. 2, the stress change due to the 2011 Tohoku-oki earthquake is less than about $1 \mathrm{MPa}$ (Yoshida et al. 2012). Therefore, we can assume almost no change in viscous deformation also for the long-wavelength components before and after the 2011 Tohoku-oki earthquake:

$$
V_{\mathrm{VL}}^{\mathrm{b}} \approx V_{\mathrm{VL}}^{\mathrm{a}}
$$

From Eqs. (A5)-(A7), we obtain

$$
V_{\mathrm{EL}}^{\mathrm{b}}-V_{\mathrm{EL}}^{\mathrm{a}} \approx d_{\mathrm{L}}^{\mathrm{b}}-d_{\mathrm{L}}^{\mathrm{a}}-V_{\mathrm{PL}}^{\mathrm{b}} \text {. }
$$

Using Eqs. (A1) and (A8), Eq. (A4) is rewritten as

$$
V_{\mathrm{PS}}^{\mathrm{b}} \approx d_{\mathrm{S}}^{\mathrm{b}}-d_{\mathrm{S}}^{\mathrm{a}}-c\left(d_{\mathrm{L}}^{\mathrm{b}}-d_{\mathrm{L}}^{\mathrm{a}}-V_{\mathrm{PL}}^{\mathrm{b}}\right) .
$$

From the comparison between Eqs. (11) and (A9), we notice that $-c\left(d_{\mathrm{L}}^{\mathrm{b}}-d_{\mathrm{L}}^{\mathrm{a}}-V_{\mathrm{PL}}^{\mathrm{b}}\right)$ represents the correction term due to elastic heterogeneity.

Because all terms of the right-hand side in Eq. (A5) are negative (recall that contraction is negative in this study), we can write

$$
d_{\mathrm{L}}^{\mathrm{b}}<V_{\mathrm{PL}}^{\mathrm{b}}<0 .
$$

Therefore, we can give the upper and lower bounds of the correction term as

$$
c d_{\mathrm{L}}^{\mathrm{a}}<-c\left(d_{\mathrm{L}}^{\mathrm{b}}-d_{\mathrm{L}}^{\mathrm{a}}-V_{\mathrm{PL}}^{\mathrm{b}}\right)<c\left(d_{\mathrm{L}}^{\mathrm{a}}-d_{\mathrm{L}}^{\mathrm{b}}\right) .
$$

The long-wavelength components of observed geodetic data, $d_{\mathrm{L}}^{\mathrm{b}}$ and $d_{\mathrm{L}}^{\mathrm{a}}$, correspond to the offset components, which were used to obtain the strain-rate profiles of Fig. 2 from the profiles of Fig. 1e, f. By taking the average of the offset components, we can have the estimates of $d_{\mathrm{L}}^{\mathrm{b}}$ and $d_{\mathrm{L}}^{\mathrm{a}}$ to be about -62 and +74 nanostrain/year, respectively. Then, with Eq. (A11) and $c$ to be about 0.05 , the range of the correction term for the plastic strain rate of the short-wavelength component is between 3.7 and 6.8 nanostrain/year. Considering that the 2011 Tohokuoki earthquake completely changed the long-wavelength deformation from contraction to extension, elastic deformation would be dominant in the long-wavelength component, $\left|V_{\mathrm{PL}}^{\mathrm{b}}\right|<<\left|V_{\mathrm{EL}}^{\mathrm{b}}\right|$. Then, the correction term is closer to 6.8 nanostrain/year.

As for the viscous strain rate of the short-wavelength component, $V_{\mathrm{VS}}^{\mathrm{a}}$, the correction term is $-V_{\mathrm{ES}}^{\mathrm{a}}$ from the comparison between Eqs. (9) and (A3). A similar equation to (A10) can be obtained as

$$
d_{\mathrm{L}}^{\mathrm{b}}<V_{\mathrm{VL}}^{\mathrm{b}}<0 .
$$

Using Eqs. (A7) and (A12), Eq. (A6) becomes

$$
d_{\mathrm{L}}^{\mathrm{a}}<V_{\mathrm{EL}}^{\mathrm{a}}<d_{\mathrm{L}}^{\mathrm{a}}-d_{\mathrm{L}}^{\mathrm{b}}
$$

From Eqs. (A1) and (A13), we can obtain the upper and lower bounds of the correction term as

$$
-c\left(d_{\mathrm{L}}^{\mathrm{a}}-d_{\mathrm{L}}^{\mathrm{b}}\right)<-V_{\mathrm{ES}}^{\mathrm{a}}<-c d_{\mathrm{L}}^{\mathrm{a}}
$$

When we use the same values as above, the range of the correction term is from -6.8 to -3.7 nanostrain/year. Because the elastic deformation should be dominant in the long-wavelength component, $\left|V_{\mathrm{VL}}^{\mathrm{b}}\right|<<\left|V_{\mathrm{EL}}^{\mathrm{b}}\right|$, the correction term would be closer to -3.7 nanostrain/year.

Received: 30 August 2019 Accepted: 24 January 2020

Published online: 13 February 2020

\section{References}

Ando M (1975) Source mechanisms and tectonic significance of historical earthquakes along the Nankai trough, Japan. Tectonophysics 27:119-140

Fukahata Y (2019) Estimate of the contraction rate of central Japan through the deformation of the Philippine Sea slab. Prog Earth Planet Sci. https:// doi.org/10.1186/s40645-018-0251-0

Fukahata Y, Matsu'ura M (2006) Quasi-static internal deformation due to a dislocation source in a multilayered elastic/viscoelastic half-space and an equivalence theorem. Geophys J Int 166:418-434

Fukahata Y, Nishitani A, Matsu'ura M (2004) Geodetic data inversion using ABIC to estimate slip history during one earthquake cycle with viscoelastic slip-response functions. Geophys J Int 156:140-153 
Gunawan E, Sagiya T, Ito T, Kimata F, Tabei T, Ohta Y, Meilano I, Abidin HZ, Agustan, Nurdin I, Sugiyanto D (2014) A comprehensive model of postseismic deformation of the 2004 Sumatra-Andaman earthquake deduced from GPS observations in northern Sumatra. J Asian Earth Sci 88:218-229. https://doi.org/10.1016/j.jseaes.2014.03.016

Hashimoto M (1990) Horizontal strain rates in the Japanese islands during interseismic period deduced from geodetic surveys (part l): Honshu, Shikoku and Kyusyu. Zisin-2 43:13-26 (in Japanese with English abstract)

Hori T, Oike K (1996) A statistical model of temporal variation of seismicity in the inner zone of southwest Japan related to the great interplate earthquakes along the Nankai trough. J Phys Earth 44:349-356

Hori T, Oike K (1999) A physical mechanism for temporal variation in seismicity in Southwest Japan related to the great interplate earthquakes along the Nankai trough. Tectonophysics 308:83-98

Ikeda Y (1996) Implications of active fault study for the present-day tectonics of the Japan arc. Active Fault Res 15:93-99 (in Japanese with English abstract)

Ito T, Hashimoto M (2004) Spatiotemporal distribution of interplate coupling in southwest Japan from inversion of geodetic data. J Geophys Res 109:B02315. https://doi.org/10.1029/2002JB002358

Kaizuka S, Imaizumi T (1984) Horizontal strain rates of the Japanese islands estimated from Quaternary fault data. Geogr Rep Tokyo Metrop Univ 19:43-65

Meneses-Gutierrez A, Sagiya T (2016) Persistent inelastic deformation in central Japan revealed by GPS observation before and after the Tohoku-oki earthquake. Earth Planet Sci Lett 450:366-371. https://doi.org/10.1016/j. epsl.2016.06.055

Meneses-Gutierrez A, Sagiya T, Sekine S (2018) Crustal deformation process in the Mid-Niigata region of the Niigata-Kobe Tectonic Zone as observed by dense GPS network before, during, and after the Tohoku-Oki earthquake. J Geophys Res 123:6072-6085. https://doi.org/10.1029/2018jb015567

Nakane K (1973) Horizontal tectonic strain in Japan (II). J Geodyn Soc Jpn 19:200-208 (in Japanese with English abstract)

Noda A, Matsu'ura M (2010) Physics-based GPS data inversion to estimate three-dimensional elastic and inelastic strain fields. Geophys J Int 182:513-530. https://doi.org/10.1111/j.1365-246X.2010.04611.X

Ohzono M, Yabe Y, linuma T, Ohta Y, Miura S, Tachibana K, Sato T, Demachi T (2012) Strain anomalies induced by the 2011 Tohoku Earthquake $\left(M_{w} 9.0\right)$ as observed by a dense GPS network in northeastern Japan. Earth Planets Space 64(12):1231-1238. https://doi.org/10.5047/eps.2012.05.015

Okada S, Ikeda Y (2012) Quantifying crustal extension and shortening in the back-arc region of Northeast Japan. J Geophys Res Solid Earth 117:B01404. https://doi.org/10.1029/2011JB008355

Research group for active faults of Japan (1991) Active faults in Japan. Sheet maps and inventories, revised edition. University of Tokyo Press, Tokyo
Sagiya T, Miyazaki S, Tada T (2000) Continuous GPS array and present-day crustal deformation of Japan. Pure Appl Geophys 157:2303-2322

Sato H (1989) Degree of deformation of late Cenozoic strata in the Northeast Honshu Arc. Mem Geol Soc Jpn 32:257-268 (in Japanese with English abstract)

Shen Z-K, Jackson DD, Ge BX (1996) Crustal deformation across and beyond the Los Angeles basin from geodetic measurements. J Geophys Res 101:27957-27980. https://doi.org/10.1029/96jb02544

Shikakura Y, Fukahata Y, Hirahara K (2014) Long-term changes in the Coulomb failure function on inland active faults in southwest Japan due to eastwest compression and interplate earthquakes. J Geophys Res 119:502518. https://doi.org/10.1002/2013JB010156

Shimazaki K (1976) Intra-plate seismicity and inter-plate earthquakes: historical activity in southwest Japan. Tectonophysics 33:33-42

Terakawa T, Hashimoto C, Matsu'ura M (2013) Changes in seismic activity following the 2011 Tohoku-oki earthquake: effects of pore fluid pressure. Earth Planet Sci Lett 365:17-24. https://doi.org/10.1016/j.epsl.2013.01.017

Toda S, Stein RS, Lin J (2011) Widespread seismicity excitation throughout central Japan following the $2011 \mathrm{M}=9.0$ Tohoku earthquake and its interpretation by Coulomb stress transfer. Geophys Res Let 38:L00G03. https:// doi.org/10.1029/2011 gl047834

Utsu T (1974) Space-time pattern of large earthquakes occurring off the Pacific coast of the Japanese islands. J Phys Earth 22:325-342

Utsu T (1990) Catalog of damaging earthquakes in the world (Through 1989). Utsu, Tokuji, Tokyo (in Japanese)

Wesnousky SG, Scholz CH, Shimazaki K (1982) Deformation of an island arc: rates of moment release and crustal shortening in intraplate Japan determined from seismicity and Quaternary fault data. J Geophys Res 87:6829-6852. https://doi.org/10.1029/JB087iB08p06829

Wessel P, Smith WHF (1998) New, improved version of generic mapping tools released. EOS Trans Am Geophys Union 79:579. https://doi. org/10.1029/98EO00426

Yamagiwa S, Miyazaki S, Hirahara K, Fukahata Y (2015) Afterslip and viscoelastic relaxation following the 2011 Tohoku-oki earthquake (Mw9.0) inferred from inland GPS and seafloor GPS/Acoustic data. Geophys Res Lett 42:66-73. https://doi.org/10.1002/2014gl061735

Yoshida K, Hasegawa A, Okada T, linuma T, Ito Y, Asano Y (2012) Stress before and after the 2011 great Tohoku-oki earthquake and induced earthquakes in inland areas of eastern Japan. Geophys Res Lett 39:L03302. https://doi.org/10.1029/2011gl049729

\section{Publisher's Note}

Springer Nature remains neutral with regard to jurisdictional claims in published maps and institutional affiliations.

\section{Submit your manuscript to a SpringerOpen ${ }^{\circ}$ journal and benefit from:}

- Convenient online submission

- Rigorous peer review

- Open access: articles freely available online

- High visibility within the field

- Retaining the copyright to your article

Submit your next manuscript at $\boldsymbol{\nabla}$ springeropen.com 